\title{
The salinity normalization of marine inorganic carbon chemistry data
}

\author{
K. Friis, A. Körtzinger, and D. W. R. Wallace \\ Institut für Meereskunde an der Universität Kiel, Marine Biogeochemistry, Kiel, Germany
}

Received 17 July 2002; accepted 9 September 2002; published 29 January 2003.

[1] Normalization to a constant salinity $(S)$ is widely used for the adjustment of marine inorganic carbon chemistry data such as total alkalinity $\left(A_{\mathrm{T}}\right)$ and total dissolved inorganic carbon $\left(C_{\mathrm{T}}\right)$. This procedure traces back to the earliest studies in marine chemistry, but ignores the influence of riverine input of alkalinity and of dissolution of biogenic carbonates in the ocean. We tested different adjustment possibilities for $A_{\mathrm{T}}$ and conclude that in most parts of the surface ocean the normalization concept does not reflect relationships which represent reality. In this paper, we propose a salinity adjustment based on a constant and region-specific term for $S=0$, which expresses river run off, upwelling from below the lysocline, calcification, and lateral sea surface water exchange. One application of the normalization concept is its extension to $A_{\mathrm{T}}$ and also $C_{\mathrm{T}}$ predictions and implementation in models. We give a brief discussion on the usage of such extensions. INDEX TERMS: 4825 Oceanography: Biological and Chemical: Geochemistry; 1635 Global Change: Oceans (4203); 1724 History of Geophysics: Ocean sciences; 4806 Oceanography: Biological and Chemical: Carbon cycling. Citation: Friis, K., A. Körtzinger, and D. W. R. Wallace, The salinity normalization of marine inorganic carbon chemistry data, Geophys. Res. Lett., 30(2), 1085, doi:10.1029/2002GL015898, 2003.

\section{Introduction}

[2] The importance of the marine $\mathrm{CO}_{2}$ system for the global carbon cycle [e.g., Bacastow and Keeling, 1973] has motivated intense field studies of ocean inorganic carbon distribution starting with GEOSECS in 1972-73 and continuing through the 1990s [e.g., Wallace, 2001].

[3] Here we critically assess a widely used but potentially biasing treatment of such data: The traditional salinity normalization. This method of adjustment of marine $\mathrm{CO}_{2}$ system parameters such as total alkalinity $\left(A_{\mathrm{T}}\right)$ and total dissolved inorganic carbon $\left(C_{\mathrm{T}}\right)$ is widely employed [e.g., Koczy, 1956; Postma, 1964; Edmond, 1974; Brewer, 1978; Chen and Millero, 1979; Poisson and Chen, 1987; Broecker and Peng, 1992; Archer and Meier-Reimer, 1994; Bates et al., 1995; Millero et al., 1998; Lee et al., 2000]. The traditional normalization is a simple transformation of a measured value $(X)$ to some reference salinity based on the measured salinity $\left(S^{\text {ref }}\right)$ (variously the mean salinity of the data in question or a salinity of 35 ):

$$
\mathrm{n} X=\frac{X}{S} \cdot S^{r e f}
$$

Originally the normalization was applied to $A_{\mathrm{T}}$ values only, but later it was extended to $C_{\mathrm{T}}[$ Postma, 1964] and calcium concentrations [Horibe et al., 1974]. The great importance of the traditional normalization concept lies in its widespread applications including: (I) comparisons between samples with different salinity, (II) constructing $\mathrm{n} X$-predictor equations as an empirical approach to describe the marine $\mathrm{CO}_{2}$ system, (III) techniques used for identifying anthropogenic $\mathrm{CO}_{2}$, and (IV) estimates of oceanic carbon transport carried by freshwater [see review by Robbins, 2001]. In the following we present a geochemical aspects of the traditional salinity normalization, demonstrate its usage and shortcomings, and propose an alternative. For the evaluation of the normalization concept we concentrate on $A_{\mathrm{T}}$ as a model parameter. However our critics applies similarly to the treatment of $C_{\mathrm{T}}$ data.

\section{Geochemical Aspects}

[4] The key processes involved in alkalinity cycling are illustrated in Figure 1. Surface alkalinity in the ocean does not behave strictly conservatively. Within the ocean, the total alkalinity can be altered as a result of, physical 'processes involving freshwater addition (dilution) or removal (evaporation, sea-ice formation) and, biogeochemical processes'. The major (but not only) biogeochemical process that affects seawater alkalinity is the cycling of carbonate minerals. Within the ocean interior, alkalinity is strongly affected by the formation and dissolution of solid carbonate minerals both in the water column and within ocean sediments. For many studies it is desirable to characterize and quantify such

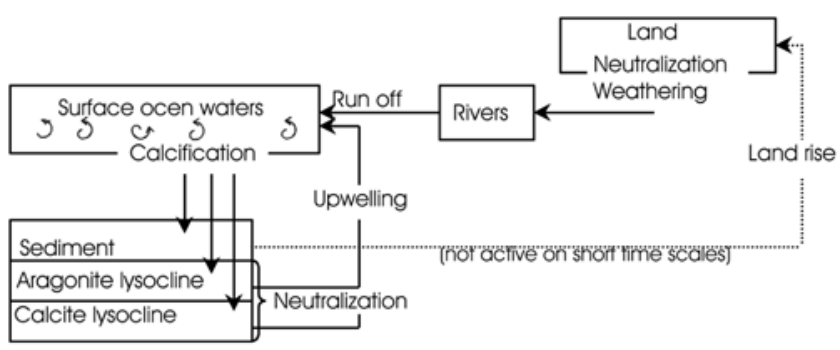

Figure 1. Schematic diagram of the relevant biogeochemical processes, that contol the dissolved carbonate salt (calcium carbonate as major part) inventory of the ocean. Neutralization is the reaction of solid carbonates with carbonic acid $\left[\mathrm{CaCO}_{3}+\mathrm{H}_{2} \mathrm{CO}_{3} \rightarrow \mathrm{Ca}^{2+}+2 \mathrm{HCO}_{3}^{-}\right]$. In context of this diagram weathering is the the reaction of silicate minerals with carbonic acid [e.g. $\mathrm{NaCaAlSi}_{\mathrm{x}} \mathrm{O}_{(2 \mathrm{x}+3)}$ $\left.\left.+2 \mathrm{H}_{2} \mathrm{CO}_{3} \rightarrow \mathrm{NaAlSi}_{\mathrm{x}}(\mathrm{OH})_{2} \mathrm{O}_{(2 \mathrm{x}}+1\right)+\mathrm{Ca}^{2+}+2 \mathrm{HCO}_{3}^{-}\right]$. -Alkalinity was historically explained as 'being a measure of its potential carbonate of lime' [Dittmar, 1884]. This interpretation has survived since the carbonate alkalinity represents the major portion $(\sim 95 \%)$ of the actual total seawater alkalinity definition. 

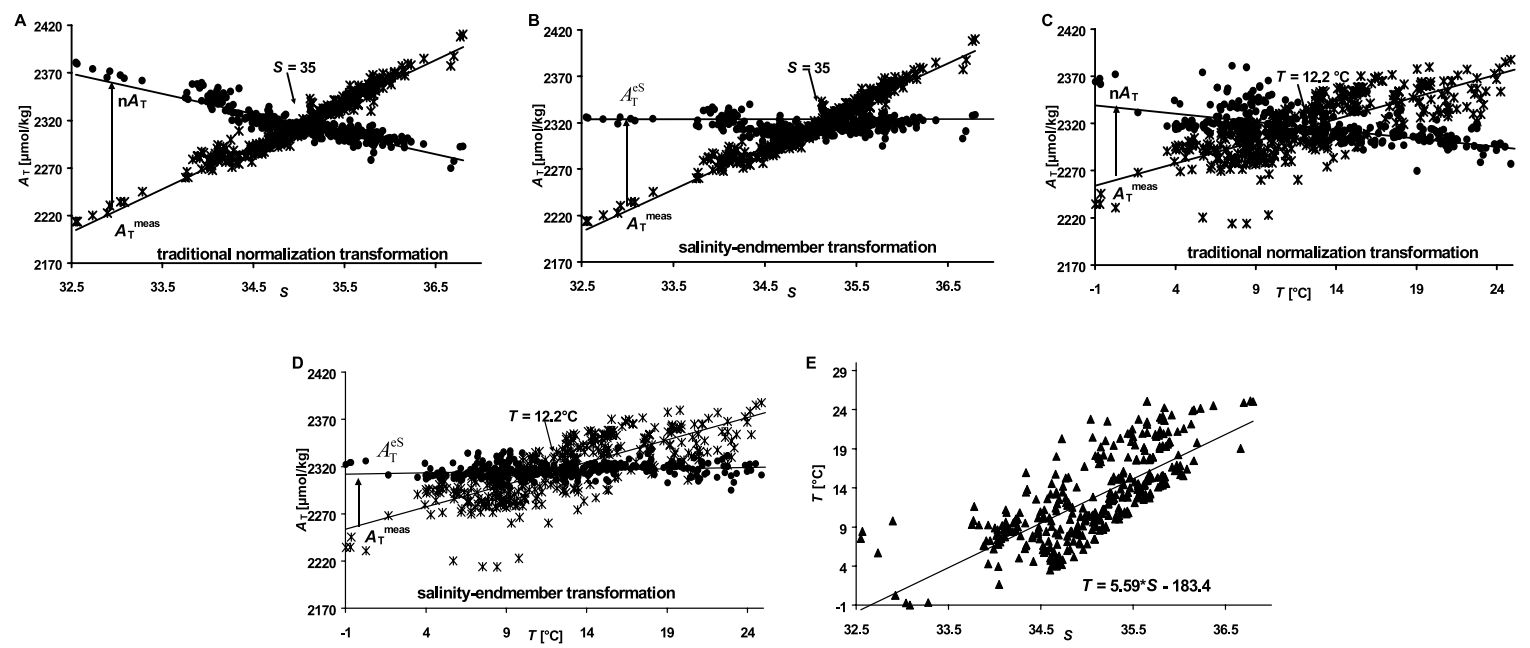

Figure 2. A-E: Relationship between alkalinity, temperature $(T)$ and salinity $(S)$ of the 'combined' data set (Atlantic between $30^{\circ} \mathrm{S}-54^{\circ} \mathrm{S}$, and north of $40^{\circ} \mathrm{N}$ excluding Norwegian and Greenland Sea): (A) Measured ( $A_{\mathrm{T}}^{\text {meas }}$, crosses) and conventional normalized alkalinity (n $A_{\mathrm{T}}$, dots) versus $S$; (B) Measured alkalinity ( $A_{\mathrm{T}}^{\text {meas }}$, crosses) and alkalinity normalized using equation $2, \#^{6}\left(A_{\mathrm{T}}^{\mathrm{es}}\right)$ versus $S$; (C) $A_{\mathrm{T}}^{\text {meas }}$ and $\mathrm{n} A_{\mathrm{T}}$ versus $T$; (D) $A_{\mathrm{T}}^{\text {meas }}$ and versus $T$, usage equation 2 , \# $\#^{6}$; (E) $T-S$ correlation.

biogeochemical processes and hence some means of separating their effect from the effect of physical factors is required.

\section{Data}

[5] Millero et al. [1998] identify surface alkalinity regimes in the world ocean. In this paper we concentrate on their regimes 2 and 6 in the Atlantic, including the Labrador Sea, but excluding the regions north of the Denmark Straight and the Iceland-Scotland Ridge. Hence we combine data from the following regions $(\mathrm{n}=356)$ : SAVE $\left(30-54^{\circ} \mathrm{S}, 15-60^{\circ} \mathrm{W}\right.$; Takahshi pers.com.; SAVE, 1992), R/V MALCOLM BALDRIGE cruise $\left(41-64^{\circ} \mathrm{N}\right.$, $\sim 20^{\circ} \mathrm{W}$; OACES, 1997), $R / V$ METEOR 39 cruise (41$62^{\circ} \mathrm{N}, 10-60^{\circ} \mathrm{W}$; Schott et al., 1999), and $R / V$ METEOR 45 cruise $\left(41-65^{\circ} \mathrm{N}, 10-60^{\circ} \mathrm{W}\right.$; Schott et al., 2000). The accuracy is similar for all data sets with $\pm 4 \mu \mathrm{mol} / \mathrm{kg}$ for SAVE [Gruber et al., 1996], $\pm 4.8 \mu \mathrm{mol} / \mathrm{kg}$ for OACES [Castle et al., 1998], $\pm 3.5 \mu \mathrm{mol} / \mathrm{kg}$ for METEOR 39 [Schott et al., 1999] and $\pm 2.0 \mu \mathrm{mol} / \mathrm{kg}$ for METEOR 45 . In order to place our results in a more global context we also make use of the eWOCE Atlas [Schlitzer, 2000] and data from the Bermuda Atlantic Time-series study [Bates, 2002]. We define surface alkalinity as the alkalinity of samples collected in the upper $50 \mathrm{~m}$ of the water column.

\section{Relationship Between Sea Surface Alkalinity and Salinity/Temperature}

[6] Based on the combined SAVE, OACES and $R / V$ METEOR surface data, we examined several different linear relationships of traditionally normalized and measured $A_{\mathrm{T}}$ with temperature and/or salinity (Table 1). Relationships $\#^{2}$ to $\#^{4}$ employ $A_{\mathrm{T}}$ values that have been traditionally normalized to a constant salinity of 35 . Relationships $\#^{1}$ and $\#^{5}$ to $\#^{7}$ use the original non-normalized $A_{\mathrm{T}}$ values. Plots of relationships $\#^{1}$ to $\#^{6}$ are shown in Figures 2A-2D.
[7] Measured alkalinity usually shows a strong salinity dependance. This is also true for traditionally normalized alkalinity (Figure 2), and this indicates immediatly that there are problems with the normalization procedure. The change in sign of the slope indicates over-correction by the normalization scheme.

[8] For relationship $\#^{6}$ (Figure 2B) $A_{\mathrm{T}}$ data have been normalized to a salinity of 35 using a non-zero freshwater endmember $\left[A_{\mathrm{T}}^{\mathrm{S}=0}=728.3 \mu \mathrm{mol} / \mathrm{kg}\right]$ according to equation (2):

$$
A_{\mathrm{T}}^{\mathrm{eS}}=\frac{A_{\mathrm{T}}^{\text {meas }}-A_{\mathrm{T}}^{\mathrm{S}=0}}{S^{\text {meas }}} \cdot S^{\text {ref }}+A_{\mathrm{T}}^{\mathrm{S}=0}
$$

No salinity-dependance of the adjusted $A_{\mathrm{T}}^{\mathrm{eS}}$ values can be observed (Figure 2B). Figure 2D also shows that $A_{\mathrm{T}}^{\mathrm{eS}}$ is independant of temperature. It thus appears that temperature doesn't play a major role for surface water $A_{\mathrm{T}}$ predictions. The anti-correlation of $\mathrm{n} A_{\mathrm{T}}$ with temperature (Figure 2C), which has been utilized frequently in the literature [e.g., Chen and Millero, 1979] can be explained

Table 1. Characteristics of empirical surface alkalinity relationships. These are derived from the 'combined' North Atlantic data set $(\mathrm{n}=356)$ and have the general form $\mathrm{n} A_{\mathrm{T}}=\mathrm{m}_{\mathrm{T}} T+\mathrm{m}_{\mathrm{S}} S+\mathrm{b}_{0}$ for traditionally normalized $\left(\mathrm{n} A_{\mathrm{T}}\right)$ and non-normalized alkalinity $\left(A_{\mathrm{T}}\right)$ $\left[\mathrm{b}_{0}=A_{\mathrm{T}}^{\mathrm{S}}=0\right]$

\begin{tabular}{cccccc}
\hline $\begin{array}{c}\text { parameter/ } \\
\text { Id }\end{array}$ & parametrization & $\sigma$ & $\mathrm{m}_{\mathrm{T}} \pm\left(\sigma^{2}\right)$ & $\mathrm{m}_{\mathrm{S}} \pm\left(\sigma^{2}\right)$ & $\mathrm{b}_{0} \pm\left(\sigma^{2}\right)$ \\
\hline$\#^{1}$ & $A_{\mathrm{T}}$ & 33.4 & - & - & $2316.8-$ \\
$\#^{2}$ & $\mathrm{n} A_{\mathrm{T}}$ & 18.2 & - & $66.2-$ & $0.0-$ \\
$\#^{3}$ & $\mathrm{n} A_{\mathrm{T}}=f(T)$ & 13.8 & $-1.7(0.02)$ & - & $2336.9(3.8)$ \\
$\#^{4}$ & $\mathrm{n} A_{\mathrm{T}}=f(S)$ & 7.4 & - & $-21.1(0.4)$ & $3056.3(39.6)$ \\
$\#^{5}$ & $A_{\mathrm{T}}=f(T)$ & 20.4 & $4.8(0.04)$ & - & $2258.0(5.6)$ \\
$\#^{6}$ & $A_{\mathrm{T}}=f(S)$ & 7.2 & - & $45.4(0.3)$ & $728.3(38.4)$ \\
$\#^{7}$ & $A_{\mathrm{T}}=f(T, S)$ & 6.7 & $0.7(0.01)$ & $41.2(0.6)$ & $865.2(51.6)$ \\
\hline
\end{tabular}

Also shown are standard deviations $(\sigma)$ of the alkalinity fits as well as variances $\left(\sigma^{2}\right)$ of $m_{\mathrm{T}}, m_{\mathrm{S}}$ and $\mathrm{b}_{0}$. 

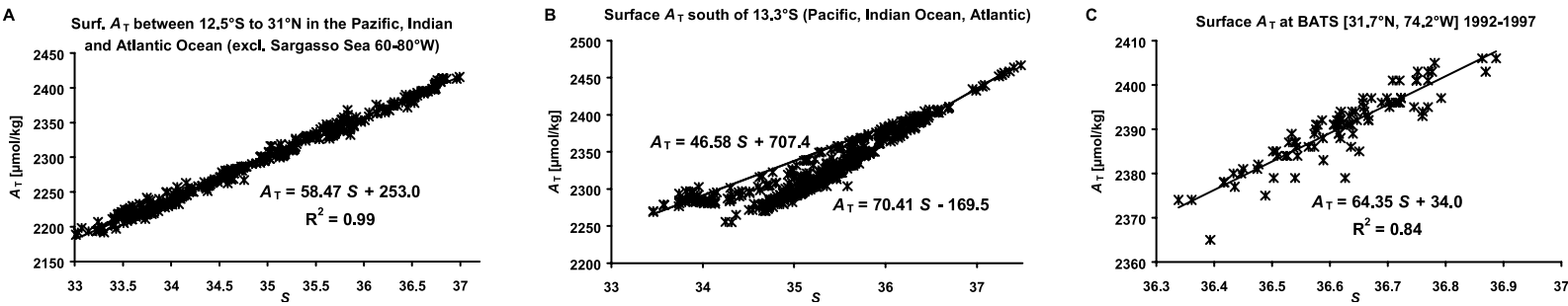

Figure 3. A-C: $A_{\mathrm{T}}-S$ relationship for samples from upper $20 \mathrm{~m}$. Panel $\mathrm{A}$ and $\mathrm{B}$ are based on data of the eWOCE-Atlas [Schlitzer, 2000]. Data prior to 1980 are not included. Panel C uses data from the Bermuda Atlantic Time Series site [Bates, 2002] that are excluded in Panel A, and where the $A_{\mathrm{T}}-S$ correlation reveals an endmember value that is close to zero.

by the $\mathrm{n} A_{\mathrm{T}}-S$ anti-correlation (Figure $2 \mathrm{~A}$ ) and the $T-S$ correlation (Figure 2E). The associative law creats a $\mathrm{n} A_{\mathrm{T}}-T$-correlation due to the strong correlation of $T$ and $S$.

[9] Therefore we propose equation (2) for the normalization of $A_{\mathrm{T}}$ to a constant salinity. The corresponding $A_{\mathrm{T}}-S$ relationship $\#^{6}$, (Figures $2 \mathrm{~A}$ and $2 \mathrm{~B}$ ) is usually very tight and yields standard deviations (here $\pm 7.2 \mu \mathrm{mol}$ $\mathrm{kg}^{-1}$ ) which compare favorably to the typical accuracy of $A_{\mathrm{T}}$ measurements at sea $\left( \pm 4 \mu \mathrm{mol} \mathrm{kg}{ }^{-1}\right)$. Even though a bivariate linear regression approach of $A_{\mathrm{T}}$ yields significant salinity and temperature correlations $\left(\#^{7}\right)$ and provides the smallest standard deviation $\left( \pm 6.7 \mu \mathrm{mol} \mathrm{kg}^{-1}\right)$ an adjustment procedure based purely on the $A_{\mathrm{T}}-S$ algorithm $\left(\#^{6}\right)$ appears adequate. This relation is able to account for the main processes determining alkalinity: Evaporation and precipitation as well as a salinity-proportional parts of mixing/upwelling and a non-zero endmember. The $A_{\mathrm{T}}-S$ relationship $\#^{6}$ may be preferred to the $A_{\mathrm{T}}-S-T$ relationship $\#^{7}$ since it avoids potential artifacts due to the seasonal temperature cycle. The alkalinity endmember (intercept) of the $A_{\mathrm{T}}-S$ relationship integrates the signals from riverine alkalinity input, deep water upwelling from beyond the lysocline(s), calcification (see Figure 1) and water mass exchange of surface waters with differing $A_{\mathrm{T}}-S$ characteristics.

[10] In fact, it is not surprising that non-zero endmember terms are found, since the size of the flux estimates of the global hydrological cycle (Figure 1) can give a rough idea of the importance of the conservative ${ }^{(\mathrm{c})}$ and non-conservative ${ }^{(\mathrm{nc})}$ processes effecting alkalinity. Baumgartner and Reichel [1975] estimated oceanic water exchanges of $425 \cdot 10^{3} \mathrm{~km}^{3} \mathrm{yr}^{-1}$ for evaporation ${ }^{(\mathrm{c})}, 385 \cdot 10^{3} \mathrm{~km}^{3} \mathrm{yr}^{-1}$ for precipitation ${ }^{(\mathrm{c})}$, leaving a balance of $40 \cdot 10^{3} \mathrm{~km}^{3} \mathrm{yr}^{-1}$ contributed by river water input ${ }^{(n c)}$. Estimates of deep water upwelling ${ }^{(\mathrm{c})+(\mathrm{nc})}$ across the $3.5^{\circ} \mathrm{C}$ isotherm are on the order of $30 \mathrm{~Sv}$ [Macdonald and Wunsch, 1996], or about $950 \cdot 10^{3}$ $\mathrm{km}^{3} \mathrm{yr}^{-1}$. Even though only part of this upwelling originates from below the lysocline (especially in the Atlantic), this large upward displacement of water inevitably has significant implications for the alkalinity budget in the surface ocean.

[11] Together with other constraints (e.g., data on river water hardness) the $A_{\mathrm{T}}-S$ relationship may even become an important tool to identify and perhaps quantify some of the processes that redistribute alkalinity in the ocean in a manner not proportional to salinity.

[12] It is not the intention of this concept study to provide a comprehensive description of the global sea surface alkalinity field. However, the quick availability of carbon chemistry data makes it possible to put the above results for the North Atlantic in a more global perspective. We find a tight $A_{\mathrm{T}}-S$-correlation for the tropics and subtropics $\left(12.5^{\circ} \mathrm{S}\right.$ to $31^{\circ} \mathrm{N}$; excluding area of Figure $\left.3 \mathrm{C}\right)$ (Figure 3A). In contrast a variable endmember situation is found for latitudes south of $13.3^{\circ} \mathrm{S}$ (Figure 3B). Finally, data from the Bermuda Atlantic Time-series study (BATS) reveal an $A_{\mathrm{T}}-S$ relationship with no significant intercept (Figure $3 \mathrm{C}$ ), and therefore no bias is produced with the traditional normalization. It is interesting to note that on the one hand tropical/subtropical regions are characterized by the same surface $A_{\mathrm{T}}-S$ relationship in the Pacific, Indian and Atlantic Ocean (Figure 3A). On the other hand, the Sargasso Sea is an exception to the same rule. At the BATS site in the eye of the Sargasso Sea $A_{\mathrm{T}}$ changes can be explained by seasonal evaporation/precipitation only. Upwelling and continental riverine inputs of alkalinity appear to play a minor role. This can be explained by station's location in the center of the subtropical gyre, i.e. in a convergent surface water regime, and by its remoteness with respect to riverine alkalinity inputs. In spite of the very consistent picture for the low latitudes, no global $A_{\mathrm{T}}-S$ relationship can be provided as the situation becomes more complex in high latitudes where multiple endmembers and significantly smaller slopes/higher intercepts are found.

\section{Discussion and Conclusion}

[13] The traditional normalization concept (equation 1) has been widely used for descriptions of the $\mathrm{CO}_{2}$-system. Our study shows that this normalization is usually not able to adjust surface $A_{\mathrm{T}}$ (nor any other carbonate parameter) for salinity variations. - A correct traditional adjustment at the BATS site appears to be the exception rather than the rule.

[14] Basically the traditional normalization is used as first step in more complex procedures or for direct interpretations. A detailed picture of all errors associated with this normalization exceeds the focus of this study. Nevertheless principle conclusions can be drawn.

[15] In high northern latitudes, or more precisely in all regions with a positive $A_{\mathrm{T}}^{\mathrm{S}}=0$ value, sea surface $A_{\mathrm{T}}$ adjustments to a salinity of 35 yields a value for $n A_{\mathrm{T}}$ which significantly departs from reality. For example, the salinity normalization using relationship $\#^{2}$ (Figure $2 \mathrm{~A}$ ) over(under)estimates the alkalinity by about $21 \mu \mathrm{mol} \mathrm{kg} \mathrm{kg}^{-1}$ per salinity unit below (above) $S^{\text {ref }}$. The usefulness of global sea surface maps for $\mathrm{n} A_{\mathrm{T}}$ [Millero et al., 1998] and $\mathrm{n} C_{\mathrm{T}}$ [Lee et al., 2000] is therefore restricted. 
[16] In fact, normalization creates artificial variance in alkalinity distributions. In turn this spurious correlation with oceanographic parameters which are salinity-correlated but unrelated with alkalinity cycling and will create errors of interpretation. For example, recognition of the spurious nature of $\mathrm{n} A_{\mathrm{T}}$ vs. $T$ correlation helps explain why, significant $\mathrm{n} A_{\mathrm{T}}-T$ relationships are not found in equatorial regions [Millero et al., 1998] where temperature and salinity are not strongly correlated [Schlitzer, 2000].

[17] The traditional normalization approach is used in the widely applied technique of Poisson and Chen [1987] for quantifying anthropogenic $\mathrm{CO}_{2}$. We would like to briefly note that despite our critique of this normalization, the errors arising from its use, for this specific application, are not large. The reason for this is that this technique uses a 'baseline' developed from temperature dependant surface pararametrizations of traditionally normalized $C_{\mathrm{T}}$ and $A_{\mathrm{T}}$ data, which are applied identically to industrial and preindustrial values. Because temperature and salinity below the mixed layer fall into narrow ranges, the $T-S$ dependent errors associated with the normalization mainly cancel out. Corresponingly, the largest errors occur in the mixed layer only.

[18] Based on the present findings we suggest that the traditional normalization concept should no longer be used, and if so only under well-defined circumstances taking into consideration local relationships, that allow an endmember term for $\mathrm{S}=0$. More generally we propose the use of an empirical relationships of the form $A_{\mathrm{T}}=\mathrm{m}_{\mathrm{S}} S+A_{\mathrm{T}}^{\mathrm{eS}}$ for the adjustment of surface alkalinity data.

[19] Acknowledgments. We want to thank Ken M. Johnson, who helped improving the manuscript.

\section{References}

Archer, D., and E. Meier-Reimer, Effect of deep-sea sedimentary calcite preservation on atmospheric $\mathrm{CO}_{2}$ concentration, Nature, 367, 260-263, 1994.

Bacastow, R., and C. D. Keeling, Atmospheric carbon dioxide and radiocarbon in the natural carbon cycle; changes from A.D. 1700 to 2070 as deduced from a geochemical model, in Carbon and the Biosphere (AEC Symp. Ser., 30), edited by G. M. Woodwell and E. V. Pecan, pp. 86-135. U.S. Atomic Energy Comission, 1973.

Baumgartner, A., and E. Reichel, Die Weltwasserbilanz, 179 pp., Oldenbourg, München, BRD, 1975.

Bates, N. R., Bermuda Atlantic Time-series Study, http:/www.bbsr.edu/ cintoo/bats/bats.html, U.S. JGOFS, 2002.

Bates, N. R., A. F. Michaels, and A. H. Knap, Alkalinity changes in the Sargasso Sea: Geochemical evidence of calcification?, Mar. Chem., 51(4), 347-358, 1995.
Brewer, P. G., Direct observation of the oceanic $\mathrm{CO}_{2}$ increase, Geophys. Res. Lett., 5, 997-1000, 1978.

Broecker, W. S., and T. H. Peng, Interhemispheric transport of carbon dioxide by ocean circulation, Nature, 356, 587-589, 1992.

Castle, R., R. Wanninkhof, S. C. Doney, J. Bullister, L. Johns, R. A. Feely, B. E. Huss, F. J. Millero, and K. Lee, Chemical and hydrographic profiles and underway measurements from the North Atlantic during July and August of 1993, NOAA data report ERL AOML-32, NOAA/AOML, Springfield NJ, 1998.

Chen, C.-T. A., and F. J. Millero, Gradual increase of oceanic $\mathrm{CO}_{2}$, Nature, 277(5693), 205-206, 1979.

Dittmar, W., Report on the scientific results of the voyage of H.M.S. CHALLANGER during the years 1873-76, Physics and Chemistry, vol. 1, published by order of her Majesty's Government, UK, 1884.

Edmond, J. M., On the dissolution of carbonate and silicate in the deep ocean, 1974, Deep-Sea Res., 21, 455-480, 1974.

Gruber, N., J. L. Sarmiento, and T. F. Stocker, An improved method for detecting anthropogenic $\mathrm{CO}_{2}$ in the oceans, Global Biogeochem. Cycles, 10(4), 809-837, 1996.

Horibe, Y., K. Endo, and H. Tsubota, Calcium in the South Pacific, and its correlation with carbonate alkalinity, Earth Planet. Sci. Lett., 23(1), 136140, 1974.

Koczy, F. F., The specific alklinity, Deep-Sea Res, 3, 279-288, 1956.

Lee, K., R. Wanninkhof, R. A. Feely, F. J. Millero, and T.-H. Peng, Global relationships of total inorganic carbon with temperature and nitrate in surface seawater, Global Biogeochem. Cycles, 14(3), 979-997, 2000.

Macdonald, A. M., and C. Wunsch, An estimate of global ocean circulation and heat fluxes, Nature, 382(6590), 436-439, 1996.

Millero, F. J., K. Lee, and M. Roche, Distribution of alkalinity in the surface waters of the major oceans, Mar. Chem., 60(1-2), 111-130, 1998.

Poisson, A., and C.-T. A. Chen, Why is there little anthropogenic CO2 in the Antarctic Bottom Waters?, Deep-Sea Res., 34(7), 1255-1275, 1987. Postma, H., The exchange of oxygen and carbon dioxide between the ocean and atmosphere, Netherlands Jour. of Sea Res., 2, 258-283, 1964.

Robbins, P. E., Oceanic carbon transport carried by freshwater divergence: Are salinity normalizations useful?, Jour. of Geophys. Res., 106(C12), 30,939-30,946, 2001.

SAVE, Chemical, physical and CTD data report, ODF-232/SIO ref 92-10 San Diego, Scripps 1992.

Schlitzer, R., Electronic atlas of WOCE hydrographic and tracer data now available, Eos Trans. $A G U, 81(5), 45,2000$.

Schott, F., K. P. Koltermann, L. Stramma, A. Sy, R. Zahn, and W. Zenk, North Atlantic 1997, cruise No. 39, 18 April-14 September 1997, METEOR-Ber., Universität Hamburg, 197 pp, 1999.

Schott, F., J. Meincke, G. Meinecke, S. Neuer, and W. Zenk, North Atlantic 1999, Cruise No. 45, 18 May-4 November 1999, METEOR-Ber., Universität Hamburg, 00-4, 161 pp, 2000.

Wanninkhof, R., S. C. Doney, T.-H. Peng, J. L. Bullister, K. Lee, and R. A. Feely, Comparison of methods to determine the anthropogenic $\mathrm{CO}_{2}$ invasion into the Atlantic Ocean, Tellus, 51B(2), 511-530, 1999.

Wallace, D. W. R, Storage and transport of excess $\mathrm{CO}_{2}$ in the Ocean: The JGOFS/WOCE global survey, in Ocean circultion and climate, edited by G. Siedler, J. Church, J. Gould, Academic Press, London, pp. 489-521, 2001 .

K. Friis, A. Körtzinger, and D. W. R. Wallace, Institut für Meereskunde an der Universität Kiel, Marine Biogeochemistry, Düsternbrooker Weg 20, 24105 Kiel, Germany. (kfriis@ifm.uni-kiel.de; akoertzinger@ifm.uni-kiel. de; dwallace@ifm.uni-kiel.) 